\title{
O debate em torno da emancipação feminina no Recife (1870-1920)*
}

\author{
Noemia Maria Queiroz Pereira da Luz ${ }^{* *}$ \\ Alcileide Cabral do Nascimento***
}

\section{Resumo}

Este artigo analisa o debate em torno da emancipação feminina no Recife, entre os anos 1870 a 1920, partindo do pressuposto de que as lutas das mulheres, feministas ou não, em Pernambuco $e$ em outros estados brasileiros não cabem mais na narrativa que nomeou esse momento como "primeira onda" do movimento. Há uma episteme sobre o feminino que colocou em foco a "questão da mulher", ressignificando e deslocando o que é ser mulher. Esse intenso debate, multiplicou as possibilidades do feminino num complexo e paradoxal movimento de construir identidade coletiva, de instituir o sujeito de direito feminino diante de um Estado que mudava a forma de governo, porém, mantinha-se conservador, oligárquico e com estreita concepção de democracia $e$ cidadania. Essas mulheres, que desbravaram espaços nitidamente masculinos e questionaram verdades em torno de seu sexo, de seu corpo e de sua inteligência, por meio da palavra escrita, publicando artigos polêmicos com ou sem pseudônimo, foram fundamentais na instituição de uma nova identidade feminina de feição moderna.

Palavras-chave: Mulheres, Feminismos, Cidadania, Relações de Gênero.

* Recebido para publicação em 27 de fevereiro de 2013, aceito em 11 de abril de 2014. Pesquisa financiada pelo CNPq e pela FACEPE.

** Profa. Dra.em História da Prefeitura da Cidade do Recife. noemialuz@terra.com.br

${ }^{* * *}$ Profa. Dra. em História da UFRPE. alcileide.cabral@gmail.com 
The Debate on the Emancipation of Women in Recife (1870-1920)

\begin{abstract}
This article analyzes the debate on women emancipation in Recife, between 1870 and 1920, assuming that the struggles of women, feminist or not, in Pernambuco and other Brazilian states, no longer fit into the narrative that named this moment as "first wave" of the movement. There is an episteme on "the feminine" that put the focus on "women's issues", resignifying what is being a woman, and moving it. This intense debate multiplied the possibilities of the feminine, in a complex and paradoxical movement in order to build collective identity and establish women as subject of rights before a country that changed its form of government, however, remained conservative, oligarchic, and with a narrow conception of democracy and citizenship. Such women - who braved distinctly masculine spaces and questioned truths about their sex, their body and their intelligence, through the written word, by publishing polemical articles, with or without pseudonyms - were essential at introducing a new feminine identity with a modern aspect.
\end{abstract}

Key-Words: Women, Feminisms, Citizenship, Gender Relations. 
cadernos pagu (42) Noemia Maria Q. P. da Luz e Alcileide C. do Nascimento 343

É comum, na historiografia feminista, dividir a luta das mulheres em dois grandes momentos, comumente denominados de primeira e segunda onda. A "primeira onda" do feminismo trata das iniciativas $e$ ações de mulheres que questionaram e enfrentaram o regime de verdade sobre seu sexo e seu intelecto, no final do século $\mathrm{XIX} e$ nas décadas iniciais do $\mathrm{XX}$, e foram capazes de conquistar o sufrágio, os direitos civis e sociais. A "segunda onda", a partir de meados dos anos 1960, aborda o momento em que as mulheres politizaram o corpo, o prazer, a sexualidade, a reprodução, e criticaram abertamente o patriarcado.

O que significa mesmo a ideia de "onda"? Quais são as implicações de se narrarem as lutas das mulheres a partir dessa metáfora? A noção de "onda" indica deslocamento de um ponto de origem, para desaguar, se espraiar mais alhures. Assinala fluxo e refluxo; agitação, tumulto; tempo curto. Na física, um de seus significados é "perturbação periódica mediante a qual pode haver transporte de energia de um ponto a outro de um material ou do espaço vazio" (Ferreira, 1986:1223). Quando aplicada à história do feminismo, a noção de onda indica movimentos que se manifestam como ondas, que irrompem em determinados tempo e lugar, deságuam em outros e se esvaem rapidamente, reforçam a ideia de centros irradiadores e suas margens, e também indicam as formas efêmeras dos movimentos feministas que acontecem de tempos em tempos, descontínuos, e se dissipam rapidamente, como aponta Suely Gomes Costa (2009:3-4). Em geral, as "ondas" provêm dos países considerados desenvolvidos do hemisfério norte, e se dirigem para o hemisfério sul, onde estariam os países subdesenvolvidos, como assinala Joana Pedro (2011:271), ao fazer a crítica à noção de "onda".

Um dos mais importantes trabalhos sobre o feminismo brasileiro, publicado originalmente em inglês, em 1990, da historiadora June Hahner, intitulado Emancipação do Sexo Feminino (Hahner, 2003), não apenas endossou essa perspectiva, quando as historiadoras nacionais ainda não tinham arado esse fértil e pouco visitado campo temático, como se tornou um discurso fundador. No entanto, sem desmerecer o esforço da 
autora para dar voz às mulheres que empunharam a bandeira da emancipação feminina desde meados do século XIX e ampliaram a estreita concepção de democracia na recém-fundada república brasileira, é preciso rever posições, contar outras histórias do feminismo, que ampliem o horizonte das batalhas e conquistas das mulheres onde pairavam as incertezas de vitórias. Essa narrativa ganhou força de verdade, a ponto de não se questionar o que foi capaz de mitificar e de silenciar o neocolonialismo ${ }^{1}$, pois, quando se olha para o mapa das conquistas femininas, o que mais chama atenção é que as mulheres conseguiram cidadania política em países distantes e dos quais pouco se ouvia falar naquele momento histórico, como Nova Zelândia (1893), Austrália (1902), Finlândia (1906) e Noruega (1913).

Desejamos aqui romper as narrativas lineares que veem nas "ondas" do movimento feminista conquistas emanadas, primeiro, dos centros ilustrados onde tudo começou - Europa, Estados Unidos - $e$, no Brasil, tendem a situar na região sudeste a primazia da luta feminista, que se espraiou para o resto do país. Ademais, é preciso outra mirada para as mulheres, sejam elas feministas ou não, que desbravaram espaços nitidamente masculinos $e$ questionaram verdades em torno de seu sexo, de seu corpo, de sua inteligência, por meio da palavra escrita, publicando artigos polêmicos com ou sem pseudônimo. Elas estavam em diversas partes do Brasil. Não se pode perder de vista o potencial subversivo dessas mulheres e do agir feminista. É preciso considerar os deslocamentos que promoveram, por vezes, mais do que a contestação.

Mulheres que se formam no ensino Normal e Superior ${ }^{2}$, que aderem às lutas abolicionistas, que ingressam no mercado de trabalho, que reclamam proteção social, que editam revistas, publicam em periódicos (Leite, 2005), organizam associações filantrópicas, que contribuem socialmente, ao mesmo tempo em

1 É instigante o artigo de Clare Hemmings (2009:215-241), que faz uma rica análise sobre as narrativas feministas em torno da "segunda onda".

2 Estudo sobre a médica baiana Francisca Praguer, ver Rago, 2005; ver também Duarte, 2005. 
cadernos pagu (42) Noemia Maria Q. P. da Luz e Alcileide C. do Nascimento 345

que ampliam sua atuação e reclamam direitos sociais e políticos. Elas descobrem outro mundo, que parece inspirar uma "consciência de gênero", como assinala Perrot (2005:279 280), e vão semeando a construção de uma nova identidade feminina moderna (Cf. Rago, 1995, 1996).

Nesse sentido, partimos do pressuposto de que há, "nos feminismos, tempos múltiplos e simultâneos por conhecer", na feliz acepção de Suely Gomes Costa, que, sustentada por Stuart Hall, ainda acrescenta: "há gerações de mulheres diferentes, que interagem em diversos estados de consciência e múltiplas identidades" (Costa, 2009:10). Precisamos inquirir essas histórias, narrar a partir da multiplicidade do olhar e sentir, dos diferentes lugares, das diversas mulheres, esse rico momento da história do feminismo no Brasil, em que se começou a rever o que é ser "mulher".

Nem todas as mulheres estavam conformadas com o papel de filhas, esposas, mães e "coquetes". Algumas queriam mais. Ressignificaram o sentido de ser mulher, fissuraram o conceito. Multiplicaram as possibilidades do feminino num complexo $e$ paradoxal movimento de construir identidade coletiva, de instituir o sujeito de direito feminino diante de um Estado que mudava a forma de governo, porém, mantinha-se conservador, oligárquico e com estreita concepção de democracia e cidadania. É esse pequeno $e$ inquieto número de mulheres que fez a diferença aqui e, como aponta Hobsbawn (1988:272), na Europa, onde a emancipação feminina terminou por produzir uma espécie de "nova mulher". Essas questões permearam o debate em torno da cidadania no regime republicano, e, como assinala Joan Scott (2002:43):

Foi em momentos revolucionários ou de transformações constitucionais que a questão dos direitos políticos esteve mais aberta a discussões, e foi sob governos republicanos que a extensão e a universalidade do sufrágio puderam ser contestadas. 
Ao combater as desigualdades social e política, as mulheres terminaram por questionar a interdição ao direito de votar e de serem eleitas. Forçaram sua abertura. Interrogaram seus pressupostos. Demonstraram o silêncio e a fragilidade jurídica em que os governos se apoiavam. Alargaram o estreito caminho da cidadania política. Exigiram passagem. Abriram veredas, mas não foi fácil.

É importante dizer que nosso saber é mesmo situado, circunscrito e localizado (Haraway, 1995:07-41). Assim, não pretendemos falar em nome do Brasil, mas contar como algumas mulheres em Recife, e quiçá de Pernambuco, desde o último quartel do século XIX, estavam profundamente insatisfeitas com sua condição de subalternidade e inferioridade frente aos homens, e como alguns homens, apesar dos pesares, passaram a ver as mulheres com outro olhar, a falar delas com outra sensibilidade. Homens raros, sem dúvida, eles deram-lhes as mãos e o apoio na imprensa escrita. Talvez, até então, não se tivesse falado tanto das mulheres. Houve uma episteme que evocou o feminino e seu referente e que problematizou a "questão da mulher". Para que servem as mulheres? Qual é seu papel? Elas são ou não inteligentes? Elas são inferiores ou não? Podem votar ou não? $\mathrm{O}$ que deve ser sancionado e o que precisa ser proibido a seu sexo? Há uma essência que informa o que é feminino e o que é masculino? O que os diferencia? O que os iguala?

Assim, o período estudado faz referência ao início das manifestações dos anseios femininos por participação como cidadãs. Cobre um tempo de transição, do Império para a República, da escravidão para o trabalho livre, época na qual a cidade do Recife se modernizava; momento em que havia crescimento do comércio, instalação de fábricas e de novos serviços $e$, principalmente, a conscientização dos valores $e$ conhecimentos das mulheres, que impulsionavam seus desejos de tomar parte efetiva na esfera da vida pública. O domínio privado foi questionado e redimensionado, e, como enfatiza Michelle Perrot (2005:459): 
cadernos pagu (42) Noemia Maria Q. P. da Luz e Alcileide C. do Nascimento 347

A distinção entre o público e o privado é, ao mesmo tempo, uma forma de governabilidade e de racionalização da sociedade do século XIX. Em linhas gerais, as esferas são pensadas como equivalentes dos sexos e jamais a divisão sexual dos papéis, das tarefas e dos espaços foi levada tão longe. Aos homens, o público, cujo centro é a política. Às mulheres, o privado, cujo coração é formando pelo doméstico e a casa.

A historiadora francesa tem razão, quando afirma que nunca se levou tão longe essa divisão entre os mundos femininos e masculinos. A vida privada de coisas essenciais, da palavra, da visibilidade, da companhia do outro, da possibilidade de realizar, passa a incomodar. Ter um "império" que alcançava o "interior doméstico", como nas prédicas do arcebispo de Reines (1879), não parece ser mais o sonho de muitas moças. ${ }^{3}$ Soa injusta $e$ absurda essa situação, mesmo às mulheres que nem sempre se diziam ou se sentiam feministas. Como assinala Hannah Arendt (2010:72):

Viver uma vida inteiramente privada significa, acima de tudo, estar privado de coisas essenciais a uma vida verdadeiramente humana: estar privado da realidade que advém do fato de ser visto e ouvido por outros, privado de uma relação "objetiva" com eles decorrente do fato de ligar-se e separar-se deles mediante um mundo de coisas, $e$ privado da possibilidade de realizar algo mais permanentemente que a própria vida. A privação da privatividade reside na ausência de outros; para estes, o homem privado não aparece, e, portanto, é como se não existisse. $O$ que quer que ele faça permanece sem importância ou consequência para os outros, e o que tem

\footnotetext{
3 Arcebispo de Reines, na íntegra: "o mais modesto papel: seu domínio é sua casa, seu império é o seu interior doméstico, seus súditos são as pessoas e as coisas que tem relação com pormenores da vida íntima", A Mulher Forte. Conferências destinadas às senhoras por MGR. Província de Pernambuco Folha Liberal, 25 set. 1879, p.3.
} 
importância para ele é desprovido de interesse para os outros.

Portanto, interessa nesse cenário investigar as seguintes questões: quais estratégias e táticas as feministas colocaram em ação para interrogar, contestar e romper com o regime de verdade sobre os sexos? como enfrentaram os poderes que ansiavam pelo controle de seus corpos e de sua sexualidade? como denunciaram os limites sexistas da cidadania no regime republicano? como lutaram pelo direito político de decidir? como alargaram as relações entre os gêneros?

\section{A cidade do Recife e as mulheres}

O último quartel do século XIX, até as primeiras décadas da República, constitui um período em que foram tomadas decisões administrativas que levaram à modernização do Recife. Esse momento foi marcado por debates no poder executivo, no legislativo e na imprensa sobre a necessidade de aparelhar a cidade com um porto capaz de atender às demandas da economia urbana e de promover a elaboração de projeto urbanístico que transformasse a cidade num espaço amplo e higiênico, com água encanada, saneamento, iluminação elétrica $e$ vias capazes de atender à circulação crescente de veículos, no compasso da modernização.

Desde meados do século XIX, havia pretensões de modificação do antigo bairro do Recife, com aterros, abertura de ruas, instalação de iluminação pública e de transportes urbanos ${ }^{4}$. No entanto, só no século $\mathrm{XX}$, os planos urbanísticos se intensificaram. Segundo Pontual e Piccolo (2008), os primeiros trabalhos urbanísticos realizados foram os Planos de

${ }^{4}$ Foram instalados desde a segunda metade do século XIX: a estrada de ferro Recife-Olinda-Beberibe (1870), serviço de telégrafos (1873), serviço telefônico manual (1881), serviço de bondes de burro (1871), serviço de bondes elétricos (1917), nova rede de esgoto (1915), tráfego aéreo Recife-Rio-Buenos Aires (1925), dentre outros (ver Rezende, 2002:100-102). 
cadernos pagu (42) Noemia Maria Q. P. da Luz e Alcileide C. do Nascimento 349

Melhoramentos e Reformas do Porto e do Bairro do Recife e o Plano de Saneamento do Recife, responsáveis pela modernização e melhoria do acesso ao porto, a abertura de três avenidas e o alargamento de outras ruas. Essas reformas foram responsáveis pela destruição de parte significativa do antigo bairro do Recife ${ }^{5}$ e se tornaram possíveis devido aos decretos de desapropriação dos edifícios. Se, de um lado, essas mudanças facilitaram a circulação dos transportes, de mercadorias $e$ pessoas, possibilitaram, por outro, maior controle sobre transeuntes, comerciantes, operários(as), prostitutas, porque estimularam a ação imediata da segurança pública, que, a partir de 1891, passou a contar com um Corpo Militar de Polícia e uma Questura Policial ${ }^{6}$ criada para auxiliar a polícia militar na prevenção e na repressão relativas aos crimes, na manutenção da ordem e na proteção dos direitos dos cidadãos.

Estima-se que a população da capital de Pernambuco chegou a aproximadamente duzentos mil habitantes entre 19101914, o que a tornava a quarta com maior população do Brasil. ${ }^{7}$ Esse aumento da população ocorreu devido ao grande contingente de imigrantes oriundos do interior de Pernambuco atraídos à capital, onde o crescimento das atividades econômicas $e$ as transformações urbanas fascinavam a população do meio rural. Para a historiadora Noemia Luz, o espaço urbano do Recife significava, para os imigrantes, além da realização do "sonho de

${ }^{5}$ Por exemplo, a demolição da Igreja Matriz do Corpo Santo, que tinha mais de 400 anos, de alguns fortes, ruas estreitas, sobrados e casarios antigos do bairro do Recife (Pontual, Piccolo, 2008).

${ }^{6}$ Sobre a estrutura administrativa de Pernambuco, recomenda-se analisar a legislação (Pernambuco, 1891:01-03).

7 Ver Braga, Carvalho, 2004. Os autores destacam que a maior parte da população brasileira, em 1900, residia nas áreas rurais, e apenas $10 \%$ viviam em áreas urbanas. Apenas quatro cidades possuíam população superior a $100 \mathrm{mil}$ habitantes: Rio de Janeiro, com 691 mil habitantes; São Paulo, com 239 mil habitantes; Salvador, com 205 mil habitantes; e Recife, com 113 mil habitantes. Porém, outros autores, como Noemia Luz (2008) e Raimundo Arrais (1997) estipulam que, entre 1910 e 1914, a população do Recife estaria em torno de 200 mil habitantes. 
350 O debate em torno da emancipação feminina no Recife (1870-1920)

morar na cidade", o desafio de "vivenciar uma série de abandonos e aprendizagens", deixando "seu lugar de origem, sua família, seus rituais" e assumindo "o novo" (Luz, 2008:63).

Com o passar do tempo, cada dia mais, as mulheres trabalham nas fábricas, no comércio e em serviços públicos e particulares. Muitas são as normalistas (A Província, 28/Nov/1877:2) ${ }^{8}$, professoras, diretoras de colégios, escritoras, redatoras de jornais, operárias, caixeiras, cigarreiras, parteiras, costureiras (Costureiras. A Província, 8/jan/1877:3) ${ }^{9}$ modistas (Madame Laura. A Pátria, 1909:1), lavadeiras, cozinheiras (Atenção. A Província, 30/jan/1877:3) ${ }^{10}$, amas de leite (Ama. A Província, 25/set/1877:4) prostitutas e cafetinas (Guerra aos caftens e cafetinas. O Prego, 27/jan/1916:3) ${ }^{11}$. Existem na cidade algumas empresárias ${ }^{12}$, donas de estabelecimentos comerciais e de serviços, médicas ${ }^{13}$ e advogadas ${ }^{14}$. Aos poucos, as mulheres de camadas médias circulavam sozinhas, a pé e de transportes nas ruas, assumiam a manutenção de suas casas $e$ alteravam a demarcação existente entre atividades femininas $e$ masculinas, entre o privado e o público.

O Recife expandia sua área urbana e criava novos espaços de sociabilidades, que encurtavam distâncias, com a instalação de

8 A matéria traz o nome das normalistas premiadas, como Florimena Joaquina de Mello Montenegro e Anna Amelia Barbosa Ribeiro, alunas do $3^{\circ}$. ano, numa época em que a escola era frequentada por homens.

9 O anúncio busca costureiras que saibam cozer à máquina para serem contratadas, levando o trabalho de costurar para fora do ambiente doméstico.

${ }^{10}$ Nesse anúncio prefere-se uma escrava.

${ }^{11}$ Inúmeras são as cafetinas do Recife. Com a modernização e o saneamento da cidade mesmo os jornais humorísticos, como $O$ Prego declaram guerra às cafetinas, denunciando seus endereços e ações, como faz com Rita Montenegro, da Rua Nova $n^{\circ} .53$.

${ }^{12}$ Noticiário de O Bem-te-vi, 14/jun/1913, p.5, informa que a Sra. D. Julia de Souza inaugurará o Café Cinema Ideal, de sua propriedade, situado à R. Coronel Suassuna $\mathrm{n}^{\circ} .11$, que oferecerá diariamente projeções cinematográficas.

${ }^{13}$ A médica Amélia Medeiros, que clinica na Rua do Rosário da Boa Vista n. ${ }^{\circ} 30$, consta no Indicador Urbano do Recife (A Reforma, 19/Nov/1904:4).

${ }^{14}$ As primeiras bacharelandas da Faculdade de Direito foram Delmira Costa, Maria Fragoso e Maria Coelho (Recife Illustrado, 10/nov/1888:1). 
cadernos pagu (42) Noemia Maria Q. P. da Luz e Alcileide C. do Nascimento 351

transportes públicos. A criação de novos espaços de encontro e a ampliação dos meios de circulação de pessoas e ideias contribuíram para as mudanças no comportamento feminino. Ver mulheres sozinhas ou acompanhadas por outras mulheres, sem a presença do pai, marido ou irmão, desbravando as lojas da cidade, aos poucos se tornaria mais frequente (Nascimento e Luz, 2012:126-149). A Revista Cri Cri, em sua Chroniqueta, captura essa moça moderna em pleno flert com os rapazes:

Cá na cidade, - ó como são belos estes dias de chuvas - ao longo das ruas populosas, moças, madames de alto coturno, demimondaines, passam apressadas, trocando com conhecidas rápidos cumprimentos, apressadas, quase correndo. Há uma espécie de alegria douda e cômica, os homens passam, tiritando, atrás das belas (Revista Cri Cri, 04/ago/1908).

\section{Rompendo silêncios: veredas incertas da emancipação feminina}

Uma imprensa brasileira feminina e feminista se constitui já no século XIX e ganha expressão nas primeiras décadas do século $\mathrm{XX}$. Em Pernambuco, as mulheres escrevem nas revistas $A$ Pilhéria, Helios, A Pátria, O Bem-te-vi, além de conseguir espaço nos principais jornais da capital, como A Província, o Diário de Pernambuco, que direta e indiretamente debatem a emancipação política feminina e assinalam, em matérias locais e vindas do exterior, o clamor contra a prepotência dos homens, cheios de incitamento à mulher, a fim de opor-lhes resistência. Como observa Maria Luiza Morais (2007:3):

Elas vão chegando devagar. Poucas tiveram uma produção expressiva, mas, incontáveis as que se fizeram presentes. Uma carta, um soneto, uma crônica, um desabafo, uma palavra solidária marcaram a entrada das mulheres no jornalismo pernambucano. 
Os artigos sobre a luta das mulheres são publicados em periódicos de diversas tendências, embora alguns jornais, em seu editorial, comuniquem ser esse o tema prioritário, como o Helios, que se propõe a apenas divulgar notícias de interesse do sexo feminino $e$ tem por seu principal dever "batalhar com intransigência pelos direitos da mulher, mantendo contínua propaganda em prol do seu desenvolvimento e do ingresso nas múltiplas atividades políticas e sociais" (Helios, 30/abril/1911:1) ${ }^{15}$.

O tema da emancipação feminina circula na cidade do Recife, na década de 1880, como parte do noticiário internacional, o qual registra a luta das mulheres por seus direitos políticos em Paris. Em 1880, A Opinião (22/abr/1880:1) ${ }^{16}$ traz artigos que contam o esforço de Hubertina Auclert e de suas amigas pelo direito ao voto. A missão dessa militante feminista francesa era "denunciar a 'mentira' de uma república que se recusa a conceder direitos políticos às mulheres", como esclarece Joan Scott (2002:155-209). ${ }^{17}$ As moças apresentaram atestado de identidade e maioridade, e requereram sua inscrição nos cadernos eleitorais, uma vez que o texto eleitoral dizia que eram eleitores todos os cidadãos franceses maiores, mas, no entanto, as mulheres maiores não puderam se inscrever. Não conseguindo a inscrição, elas optaram por assinar e divulgar protesto, no qual escreveram que, quanto ao direito do voto, "só a questão do sexo nos pode ser oposta". Argumentaram ainda que "a sociedade moderna (...) não deve mais consentir em que metade da humanidade, as mulheres, sejam hereditariamente condenadas à privação dos direitos cívicos" (A Opinião, 22/abr/1880:1).

A primeira matéria que encontramos sobre a questão do voto feminino na imprensa do Recife data de 1872, quando Severino Cardoso (A Verdade, 23/nov/1872:2-3) critica a

\footnotetext{
${ }^{15} \mathrm{O}$ corpo redacional contava com Maria e Blandina A. Vasconcelos, Guilermina de Andrade e Eloisa Bittencourt.

${ }^{16}$ Assinaram o manifesto Humbertina Auclert, Aube, Conrthier, Blin, Cenly, Maria Droin, Bastieu, Blane, Eugenie Pierre, Leulep, Boucker. Mulheres Eleitoras. ${ }^{17}$ Ver a propósito o excelente estudo de Joan Scott (2002:155-209) sobre a feminista.
} 
cadernos pagu (42) Noemia Maria Q. P. da Luz e Alcileide C. do Nascimento 353

constituição vigente no Império, por conceder à mulher o direito à sucessão do trono, e retirar de todas as outras o direito eleitoral.

A repercussão da luta pelo voto leva jornais como Mephistopheles, em 1882, a profetizar sobre a questão com ironia, argumentando que a equiparação jurídica livrará os homens da:

\begin{abstract}
(...) obrigação legal de ter que casar-se sempre com mulheres, podendo escolher para a mãe de seus filhos, segundo suas afeições e seus gostos, doutores em medicina, advogados, soldados, náuticos, (...) ou o presidente do Conselho de Ministros (A Emancipação das Mulheres. Mephistophesles, 10/set/1882:3).
\end{abstract}

$\mathrm{O}$ artigo ainda destaca $\mathrm{o}$ fato de ser a mulher economicamente um "fausto ruinoso" para os homens, que em troca de filhos os obrigam a lhes amparar e sustentar. Que estudem, trabalhem e ganhem dinheiro para sua manutenção e de sua família (Mephistophesles, 10/set/1882:3). Os homens temem a emancipação feminina. Desdenham-na. Acusam o estorvo da obrigação legal de manter mulher e filhos. Ameaçam romper esse pacto. $\mathrm{O}$ casamento soa como uma difícil e escorchante obrigação.

Como se sabe, a participação das mulheres no debate político em Pernambuco ganha visibilidade nos anos efervescentes da campanha abolicionista. Convocadas para a luta as mulheres participaram das mais variadas formas, dentre as quais se destacaram, no Recife, os encontros do Club do Cupim $^{18}$, a ação da Sociedade Ave Libertas (Grillo, 2005) e a presença em diversas conferências pró-abolição, entre elas as proferidas por José Mariano Carneiro da Cunha e Joaquim Nabuco, realizadas no teatro Santa Isabel, local de encontro dos abolicionistas (Nabuco, 2005:251). Como destaca Ângela Alonso (2007:188): "Mesmo sem

\footnotetext{
18 Sobre o Club do Cupim, fundado em 8 de outubro de 1884, Leonardo Dantas Silva explica que o nome deriva do caráter abolicionista que tinha o Clube que "ia trabalhar na sombra a coberto das vistas alheias, e minar carcomendo roaz $e$ minaz, o próprio cerne da nefanda árvore da escravidão” (Silva, 1988:28).
} 
voto, as mulheres ganharam destaque, com camarotes reservados no Santa Isabel para ver Quincas, o Belo, de perto".

Em 19 de abril de 1890, Maria Augusta C. Meira de Vasconcellos, escritora, advogada, bacharel em Direito e Ciências Jurídicas pela Faculdade de Direito do Recife, uma das primeiras a obter esse título no país, redige um artigo $e$ o faz publicar no Jornal do Recife, questionando a decisão do Ministro do Interior de não permitir que as mulheres votem. Maria Augusta relata que, recorrendo aos jornais de Pernambuco, encontrou matéria que afirma: "O Sr. Ministro do Interior, em resposta à consulta que lhe foi dirigida por uma comissão distrital, vai declarar que as senhoras não têm o direito de voto". Ela informa ainda que, lendo a Epocha de 6 de abril de 1890, encontrou telegrama do Ministério respondendo à comissão distrital de Itabapoana, que pergunta se deve incluir no alistamento eleitoral algumas senhoras que $\mathrm{o}$ requereram, que "o regulamento eleitoral vigente, assim como a legislação anterior não cogitou de conferir às mulheres o direito do voto" (Vasconcellos, 1890:2). Diante dessas informações, a advogada argumenta que o governo só permitiu que as mulheres cursassem a faculdade para ter direitos aos impostos cobrados com a matrícula e que ela continuará na propaganda em favor da emancipação feminina. Conclama as senhoras que pagam impostos, as professoras públicas tituladas, as empregadas públicas e demais pernambucanas e brasileiras a se animar $e$ perseverar na luta pelo direito que as assiste, no momento em que o direito ao voto foi estendido pela ampliação da lei eleitoral às classes menos favorecidas:

A vós todas as senhoras, que contribuis com os impostos para o Estado, a vós professoras públicas tituladas, a vós empregadas públicas e quantas pernambucanas ilustres $e$ brasileiras em geral, ergo o brado da animação para que com a máxima perseverança e renhida pertinácia me ajudeis na construção deste grande monumento para fazer florescer o direito que nos assiste (Vasconcellos, 1890:2). 
cadernos pagu (42) Noemia Maria Q. P. da Luz e Alcileide C. do Nascimento 355

Ainda, pergunta por que motivo a República, que todos os dias faz leis, ampliou um benefício a uns e o restringiu a outros? A quem isso beneficia?

As ações internacionais em favor da emancipação das mulheres e seus desdobramentos repercutem no Recife, levando, em 1890, Xavier de Carvalho a publicar, no Jornal do Recife, artigo que destaca como "um dos mais altos e dos mais profundos problemas a resolver no fim do século a emancipação econômica, política e social da mulher" (Carvalho, 1890:1). ${ }^{19}$ A matéria registra a fundação, em Paris, de uma associação intitulada Union Universelle dês Femmes, organizada em comissões, dentre as quais se destaca a dos direitos políticos das mulheres, que se ocupa das questões pendentes quanto aos direitos da mulher na família, na comuna e no Estado.

O debate em torno do sufrágio feminino toma vulto com a proclamação da República, em 15 de novembro de 1889. O problema, que já se coloca nos anos iniciais do regime republicano, é a estreiteza com que se compreende a cidadania e a noção de esfera pública moderna, na vigência da "República dos Coronéis", na qual só votam homens, maiores de 21 anos e alfabetizados, em eleições duvidosas. Afinal, onde reside a diferença entre homens e mulheres que alimenta a exclusão feminina da arena política? Esse parece ser $o x$ da questão colocada por diferentes feministas do Recife e de outras capitais, onde as mulheres discutem e questionam sua exclusão dos espaços públicos de decisões políticas. São os novos tempos, com aspirações, sonhos, inquietações e frustrações. Sim. Frustrações datadas, inclusive, quando as mulheres foram esquecidas $e$ silenciadas na Constituição de 1891, art. 70, que estabeleceu o sexismo político, ao sancionar que apenas cidadãos, maiores de 21 anos e alfabetizados seriam considerados eleitores. Mas, quem eram os "cidadãos"? Esse não é um termo universal que supõe a

\footnotetext{
${ }^{19} \mathrm{O}$ artigo também compara a vida da mulher na França e em Portugal, comenta sobre a imprensa destinada aos interesses femininos na Inglaterra, na Alemanha e nos Estados Unidos.
} 
inclusão das mulheres? No momento do alistamento eleitoral, apenas os homens entravam nessa categoria.

Portanto, a data de promulgação da constituição é um marco para se execrar e exaltar ao mesmo tempo. Se as mulheres já se pronunciavam sobre seus direitos e desejos, já se imiscuíam na campanha abolicionista, ousavam publicar revistas $e$ periódicos, como algumas pesquisas mostram (Hahner, 2003; Siqueira et al., 1995; Morais, 2007; Barbosa, 2012), a lei republicana, portanto, foi mesmo excludente, ao não considerar a mulher como sujeito de direitos. Assim, pode-se dizer que a data é execrável, mas, ao dar visibilidade à disparidade entre os sexos, termina por fortalecer as reivindicações $e$ os movimentos feministas. Nesse sentido, a afirmação de Joan Scott de que "o feminismo não é produto das operações benignas e progressistas do individualismo liberal, mas um sintoma de suas contradições" (Scott, 2002:48) ganha força também no Brasil.

Não há dúvida de que, no país, os movimentos feministas tomam fôlego na Primeira República, regime oligárquico e liberal. Mas isso só é possível nos marcos de um Estado que se propõe a ser democrático, no qual a liberdade é um dos princípios norteadores de sua constituição. E as mulheres instrumentalizaram esse espaço da liberdade e da crítica. A intensa utilização da imprensa, do rádio e a criação de jornais e revistas pelas feministas falam, por si, de novas práticas de liberdade (Foucault, 2004:267) e de deslocamentos de jogos de poder. Provocam, questionam, apontam caminhos de convivência entre os sexos, redefinindo campos de relações de poder entre os gêneros, descortinando novos horizontes para mulheres e homens.

$\mathrm{Na}$ Constituição republicana, o direito de votar não é explicitamente negado à mulher, aliás, sequer a mulher é citada, já que os constituintes entendiam que a mulher não é um sujeito possuidor de direitos, como a historiografia vem enfatizando (Pinto, 2002:15-16). Contudo, o dado novo no debate é a questão colocada por Anne Verfus (2005:428), ao aclarar que "a cidadania oriunda da abolição do sufrágio censitário fez emergir com uma visibilidade sem precedentes a separação política entre os homens 
cadernos pagu (42) Noemia Maria Q. P. da Luz e Alcileide C. do Nascimento 357

$e$ as mulheres" [grifo da autora], ao fazer aparecer o voto individual masculino em 'idade viril' e a não inclusão das mulheres no corpo eleitoral. O sexismo, que, como princípio político, faz uso do discurso da diferença natural entre os sexos para justificar as desigualdades em matéria de direitos políticos (Verfus, 2005:430), torna-se um problema para o regime republicano brasileiro e vira bandeira de luta dos movimentos feministas que dão seus primeiros passos no território nacional $e$ em outras partes do mundo.

Jornais do interior de Pernambuco e de outros estados que circulam no Recife apresentam notícias da luta pelo voto no mundo. Alguns acrescentam à nota uma crítica à ação das mulheres, mas a informação com frequência chega aos leitores com dados significativos sobre os encaminhamentos do movimento sufragista feminino internacional. $O$ Lidador (18/mar/1912:1), de Vitória (PE), publica artigo que informa sobre o movimento reclamando o direito de voto na Inglaterra e na Itália. ${ }^{20}$ O Pharol (O Feminismo na América. O Pharol, 1/maio/1909:4) de Bananeiras, na Paraíba, comenta a notícia divulgada nos jornais estrangeiros sobre a reunião em Nova Iorque, sob a presidência de Carrie Chapman $\mathrm{Catt}^{21}$, que levou as sufragistas americanas a estabelecer uma liga semelhante à de Londres e a participar de uma campanha análoga a das sufragistas inglesas. Informa também que as americanas promoveram conferências, comícios e resolveram não pagar nenhuma contribuição, enquanto não lhes for concedido o direito do voto. A estratégia é usar a imprensa, para divulgar as campanhas sufragistas em outros países, formar opiniões $e$ ir tecendo uma atmosfera propícia ao

\footnotetext{
${ }^{20} \mathrm{O}$ artigo $\mathrm{O}$ Feminismo, de $\mathrm{O}$ Lidador, divulga em primeira página uma crônica publicada pelo jornal O Propulsor, da cidade de São Félix na Bahia.

${ }^{21}$ Uma das líderes norte-americanas da campanha sufragista atuou como presidente da Associação Nacional de Sufrágio de Mulheres Americanas e foi fundadora da Liga das Mulheres Eleitoras e da Aliança Internacional das Mulheres. Nos Estados Unidos, as mulheres conseguiram o direito do voto em 1920. Disponível em: <http://womenshistory.about.com/od/cattcarriec/p/carrie_catt.htm>. Acesso em: 10 maio 2010.
} 
sufrágio feminino. Isso exigiu muita articulação política e um regime democrático - embora oligárquico, excludente e machista - que permitisse a circulação das mulheres, suas ações, sua rebeldia.

Essas mobilizações ganham extensão. Chegam às organizações operárias, que não escapam da discussão sobre os direitos femininos. Em 1903, segundo notícias do jornal Aurora Social (Nascimento, 1966:36) ${ }^{22}$, o Centro Operário cria e anuncia em primeira página a Secção Feminina, cuja fundação foi celebrada numa das salas do Centro Operário, com reunião das operárias, em ato presidido por Francisco Britto (Secção feminina. Aurora Social, 13/abr/1903:1). Constituem-se Secção Feminina as agrupações feministas que se propõem, segundo o estatuto redigido e publicado pelo Centro Protetor dos Operários de Pernambuco, a:

\begin{abstract}
a- Defesa dos direitos da mulher operária e elevação do seu caráter; b- Auxiliar pecuniariamente as operárias que constituírem família; c- Defender o pudor da mulher, constituindo-se toda a coletividade em guarda vigilante; $\mathrm{d}$ Reclamar direitos civis para a mulher e auxiliá-la em toda altura na proclamação de suas prerrogativas; $e$ - Distribuir socorro entre elas e prodigalizar lunares de felicidade (Estatutos... Aurora Social, 21/dez/1903:3).
\end{abstract}

O que se observa no estatuto acima são os valores de uma ordem falocêntrica: "defesa do pudor" feminino, "elevação do seu caráter", "socorro", dentre outras afirmativas que veem a mulher como frágil, física e moralmente. Em nenhum momento, coloca-se $\mathrm{o}$ acesso ao direito à igualdade política com os homens. Margareth

\footnotetext{
${ }^{22}$ Aurora Social. Órgão do Centro Protetor dos Operários. Diretor João Ezequiel. O jornal de tendência socialista afirmava não ser vinculado a partidos, mas existia para combater "a exploração que, em nome do operariado pernambucano, vai fazendo a burguesia hodierna". O primeiro número é de 19 de janeiro de 1903, quando publicou um longo "Manifesto do Conselho Geral do Partido Socialista Brasileiro aos habitantes do Brasil, especialmente aos proletários". Na edição seguinte, inseria as resoluções tomadas no Segundo Congresso Socialista Brasileiro, realizado em São Paulo.
} 
cadernos pagu (42) Noemia Maria Q. P. da Luz e Alcileide C. do Nascimento 359

Rago (1985:67) chama a atenção para que "o discurso operário masculino fala da e para a mulher trabalhadora" e, ao atribuir o "direito de liderança sobre as mulheres, mesmo o anarquista", fálo em nome da sua "débil atribuição física" e da "falta de combatividade que caracteriza 'a natureza feminina". A emancipação feminina não foi uma bandeira do movimento operário, nem em Recife nem em outras capitais, como atestam os estudos até então realizados (Rago, 1985; Besse, 1999), dentre os quais o de Susan Besse (1999:10) enfatiza:

\begin{abstract}
O apoio sindical à legislação protetora - que em última análise, contribuía para preservar o espaço dos homens no mercado de trabalho - impunha estereótipos de fragilidade feminina às mulheres que haviam enfrentado turnos de trabalho brutais, garantia o trabalho doméstico de mulheres sem pagamento e contribuía para impor à classe operária urbana o modelo de família burguesa.
\end{abstract}

O Centro Protetor dos Operários tem por proposta a formação de sucursais e a colocação de seus representantes na Federação Socialista que se organiza no Recife (Aurora Social, 13/abr/1903:1). Tal proposta é significativa para as mulheres que participam da Secção Feminina, por permitir que algumas sejam diretoras, quando executarem as funções de delegado nas sucursais (Aurora Social, 21/dez/1903:3). A despeito do espaço de luta criado nas reuniões da Federação Operária Brasileira e nos congressos operários da época, dentre os representantes do Recife, não consta a presença feminina (Aurora Social, 21/dez/1903:3).

$\mathrm{O}$ acesso à luta feminina tem preço: a joia cobrada pelo Centro Protetor dos Operários de Pernambuco é de $8 \$ 000$ e a mensalidade, de $1 \$ 000$, dos quais 300 réis vão para o órgão geral da corporação (Aurora Social, 21/dez/1903:3). Cabe refletir sobre o crescimento do emprego das mulheres no mercado de trabalho do Recife e a necessidade de órgão criado para organizar os/as trabalhadores/as, como o Centro Protetor dos Operários de Pernambuco, de agregar as lutas das mulheres e os recursos 
provenientes de seus serviços. As mulheres são importantes e as lideranças operárias masculinas as assimilam como seus representantes. Nessa relação de gênero, é visível a subordinação feminina, já que as operárias são vistas como incapazes de "assumirem a direção de suas vidas individuais ou enquanto grupo social oprimido" (Rago, 1985:69).

Nos Estatutos do Centro Protetor dos Operários de Pernambuco (Aurora Social, 21/dez/1903:3), destacamos, dentre as regras das Secções Femininas, o auxílio pecuniário às mulheres que constituírem família, dotando-as com a quantia de 50\$000, o que se fará mediante certidão civil, única prova do matrimônio, enquanto outra não for coordenada. Aqui a organização protetora dos operários registra a aceitação apenas do casamento civil, e se subentende seu questionamento quanto à validade do casamento religioso, ao mesmo tempo em que reforça a norma e o ideal de família burguesa.

O debate em torno das diferenças entre homens e mulheres ganha novas nuanças com a presença do pensamento positivista na escrita de mulheres como Maria Augusta de Vasconcelos Fragoso. Em 1904, a advogada publica um fascículo intitulado A Questão da Mulher, em que discute se a mulher é inferior ou igual ao homem. Em sua concepção, não se pode afirmar que o sexo feminino é superior ao masculino nem que é igual. Para a advogada e escritora:

Homem e mulher são naturezas indispensáveis, reciprocamente necessárias uma a outra. Cada sexo é complemento do outro, porque cada um deles possui funções especiais, cuja união íntima e solidária constitui a unidade humana, o par, que é o ser eminentemente social (Fragoso, 1904:04).

Nesse sentido, a autora considera falácia negar os direitos políticos às mulheres porque teriam "falta de exercício cerebral". Essa afirmação apenas escamoteia o que se lhes nega socialmente. Sua análise inverte a assertiva: "É ir de encontro à natureza 
cadernos pagu (42) Noemia Maria Q. P. da Luz e Alcileide C. do Nascimento 361

humana pretender assimilar os sexos ou estabelecer a superioridade de um sobre o outro" (Fragoso, 1904:05). Apoiando-se em Augusto Comte e em Durkheim, que consideram que o espírito humano só se desenvolve em sociedade, ela entende que não se deve resolver a questão da mulher apontando apenas a dimensão psicológica individual, mas atentar para as condições da vida social na qual ela está inserida. Há um meio físico e social que precisa ser levado em conta. Seu discurso caminha para o sentido da complementaridade entre os sexos, combatendo aqueles que só veem concorrência $e$ inferioridade entre mulheres e homens.

Nem todos os homens eram contrários à emancipação feminina. Em artigo publicado na revista Polyantho, o poeta Layette Lemos acredita que as mulheres conquistarão a vitória. Em sua compreensão, a arena política era mesmo o lugar de maior resistência à entrada das mulheres:

O mundo político é anfiteatro imenso. (...) E a mulher que tem alcançado nesse círculo social, vários lugares, sente-se forte e redobra-se de sacrifícios para tomar de assalto a fronteira política, onde se acha o reduto de seus adversários (Lemos, 1907:3).

Mesmo em jornais nos quais encontramos matérias a favor da luta política das mulheres, há outras que questionam se há necessidade da emancipação da mulher, e respondem a essa pergunta com a afirmativa:

(...) a nossa civilização não comporta, a nossa organização social sabiamente não permite, a própria organização feminina não se coaduna, em suma os deveres sagrados da mulher na família clamam contra isto a que chamamos a emancipação política da mulher (Jornal da Semana, 24/jan/1911:1).

Artigos alertam as mulheres de que a luta por igualdade é uma luta contra a índole e a natureza feminina, ressaltam que a harmonia social é fundada na diferença. Argumentam que a 
mulher não deve exercer funções públicas e estabelecer a igualdade com os homens, no que diz respeito a assegurar seus direitos individuais, porque elas têm organismo anatomicamente e fisiologicamente diferente, possuem "instintos mais seguros $e$ inteligência menos desenvolvida" (Caracciolo, 1903:20). Outros advertem como limite para a atuação política o fato de as mulheres estarem sujeitas a alterações em seu estado mental, como a neurastenia e a hipocondria nervosa. Em resposta a essa posição do Jornal da Semana (Emancipação da Mulher, Jornal da Semana, 12/ago/1911:1) - que, comungando com alguns jornais da cidade, com frequência, aponta os limites físicos e psicológicos das mulheres como impedimento a sua participação política - o jornal Helios, na edição de 30 de julho de 1911, afirma que estados patológicos são comuns aos dois sexos e "a habilitação para a política vem da prática".

Havia mesmo disposição feminina para a lida política. $\mathrm{Na}$ acirrada campanha eleitoral de 1911, conhecida como Campanha Salvacionista, que conduziu o General Dantas Barreto ao governo de Pernambuco, desbancando a oligarquia chefiada pelo Conselheiro Rosa e Silva (Arrais, 1998:13) com ampla participação popular nunca dantes vista, as mulheres foram chamadas a dar apoio e influenciar a disputa política ao lado de Dantas Barreto. $\mathrm{O}$ jornal A Pátria, de Garanhuns,, em artigo assinado por E. Leão, sob o título As Mulheres e a Política, chama atenção das mulheres para que "trabalhem pela reabilitação da classe" $e$ vinculem seu apoio ao direito do voto. $\mathrm{O}$ articulista ainda lembra que Dantas Barreto nunca defendeu os direitos das mulheres (Leão, 1911:1). Mesmo advertidas, senhoras e senhorinhas da sociedade pernambucana empunham armas, em plena rua, nessa disputa eleitoral (Melo, 1938:77). ${ }^{23}$ É uma cena fantástica de coragem, força e ousadia das mulheres. Embora não vinculem diretamente essa participação no processo eleitoral ao apoio da causa feminina, elas mostram que podem utilizar o recurso das armas para defender seu candidato.

${ }^{23}$ Foto publicada com o título o heroísmo da mulher pernambucana. 
cadernos pagu (42) Noemia Maria Q. P. da Luz e Alcileide C. do Nascimento 363

\section{Considerações finais}

As cidades dos anos 1920 tornam-se palco de uma nova configuração social. Por volta de 1922, é fundada no Rio de Janeiro, a Federação Brasileira para o Progresso Feminino, sob a liderança de Bertha Lutz, marco da ampliação da luta das mulheres no país pela conquista do direito de votar (Cf. Pinto, 2002:21-28; Teles, 1999:44). É uma década de conflitos em torno da virgindade, das uniões consensuais e dos crimes passionais estampados nos jornais. É também o fortalecimento do ideal burguês de família, ganhando materialidade e ocupando territórios, em confronto com a família patriarcal.

A modernidade e a tradição travam intenso diálogo no Recife e em várias cidades brasileiras. Gilberto Freyre é um dos escritores que captam essa mudança. No Manifesto Regionalista, de 1926, ele lamenta a decadência da tradição:

As novas gerações de moças já não sabem, entre nós, a não ser entre a gente mais modesta, fazer um doce ou guisado tradicional e regional. Já não têm gosto nem tempo para ler os velhos livros de receitas de família. Quando a verdade é que, depois dos livros de missas, são os livros de receitas de doces e de guisados os que devem receber das mulheres leitura mais atenta. $\mathrm{O}$ senso de devoção e o de obrigação devem completar-se nas mulheres do Brasil, tornando-as boas cristãs, e, ao mesmo tempo, boas quituteiras, para assim criarem melhor os filhos e concorrerem para a felicidade nacional. Não há povo feliz quando às suas mulheres falta a arte culinária. É uma falta quase tão grave como a da fé religiosa (Freyre, 1926. S/P).

la longe o tempo em que as moças de família se interessavam por novenas e livros de receitas de doces tradicionais e queriam ser "anjos do lar". Como dizia Drumond, "quem pode vigiar sonhos de moça?" (Andrade, 2001:137). Elas desejavam e ousavam mais: educar-se. Ter profissão. Participar politicamente das decisões. Ter uma vida pública. Direitos iguais aos homens. 
Cidadania. Trabalho. Respeito. Assim, June Hanner (2003:31), ao afirmar que a luta pelo sufrágio no Brasil foi "um movimento de classe média, em prol de uma mudança jurídica para garantir o voto daquelas que haviam alcançado a mesma qualificação que os homens", tem razão em parte. Mas, mesmo que não tenham tido a intenção de "revolucionar o papel da mulher na sociedade, nem a própria sociedade em si" (Hanner, 2003:31), como diz a autora, promoveram rupturas importantes ao questionar e romper com o discurso que naturalizava a diferença entre homens e mulheres.

Sem dúvida, nas lutas e nos embates travados ao longo desses anos, houve mesmo um viés de classe média. Para essas mulheres e moças, muitas de famílias abastadas, a conquista da cidadania política levaria à ampliação dos direitos sociais e civis $e$ ao deslocamento dos pleitos para o parlamento. Como vimos, a pressão pela proteção e pelos direitos sociais no Recife vem do Centro Operário. Nessa organização sindical, as igualdades política e jurídica entre homens e mulheres não são centrais. Ao contrário, a subordinação feminina às lideranças operárias masculinas é enfatizada.

$\mathrm{O}$ que não podemos continuar afirmando, de forma quase mítica, é que essas lutas, os embates, a intensa utilização da imprensa, falada e escrita, as estratégias e táticas colocadas em ação a cada virada do jogo, o amadurecimento da consciência do lugar de submissão, em que as mulheres se encontravam, não fissuraram o papel da mulher na sociedade. É preciso visualizar os deslocamentos, o potencial de resistência, de instituição e de novos significados nas relações de e entre os gêneros, como um dos ganhos dessas ações. As mulheres agiam isoladamente ou, por vezes, agrupadas pela amizade. Suas ações são localizadas. Nem todas se autonomeavam feministas. Não criaram organizações políticas estratégicas, como se faria na década de 1920. Mas, foram essas mulheres, feministas ou não, fundamentais na instituição de uma nova identidade feminina de feição moderna.

Em artigo recente sobre a conquista do espaço público pelas mulheres, Rachel Soihet reavalia o amplo significado dessa luta: 
cadernos pagu (42) Noemia Maria Q. P. da Luz e Alcileide C. do Nascimento 365

Mesmo que hoje suas posturas possam ser alvo de críticas, o que fizeram já foi um grande avanço: as mulheres passaram a ser pensadas para além dos papéis familiares como pessoas com capacidades profissionais, intelectuais $e$ com possibilidades de eleger representantes e de ocupar elas mesmas cargos públicos (Soihet, 2012:234).

Mesmo sem questionar a maternidade como a grande missão feminina, as mulheres ativistas, feministas ou não, terminaram por concorrer para romper com a naturalização da desigualdade e da diferença entre os sexos, com a dominação e com os privilégios dos homens. $\mathrm{O}$ medo de que mudassem a "ordem da sociedade" se confirmou. Como declarava Nina Centi, em 1923, na revista Pilhéria (1923:14), "Hoje, em dia, quando a mulher se vê só e sem fortuna, ela trabalha, ela luta e ela vence".

\section{Referências bibliográficas}

AlONSO, Ângela. Joaquim Nabuco: o salão e as ruas. São Paulo, Cia das Letras, 2007.

ANDRADE, Carlos Drummond. Presépio. In: MoRICONI, Ítalo (org.). Os cem melhores contos brasileiros do século. Rio de Janeiro, Objetiva, 2001.

ARRAIS, Raimundo Pereira Alencar. O Periquito: uma revista licenciosa no Recife da entrada do século XX. Revista do Arquivo Público, Recife-PE, dez. 1997, pp.10-23.

. Recife: culturas e confrontos. A participação na campanha salvacionista de 1911. Natal, EDUFRN, 1998.

ARENDT, Hannah. A condição humana. Rio de Janeiro, Forense Universitária, 2010.

BARBOSA, Izabelle Lúcia de Oliveira. Entre rastros e rostos: Ascensão das mulheres nas revistas recifenses no início do século XX. Prêmio Naíde Teodósio de Estudos de Gênero, Ano V, Recife, Secretaria da Mulher, 2012.

BESSE, Susan. Modernizando a desigualdade. Reestruturação da ideologia de Gênero no Brasil, 1914-1940. São Paulo, EDUSP, 1999. 
366 O debate em torno da emancipação feminina no Recife (1870-1920)

Braga, Roberto; Carvalho, Pompeu Figueiredo de. Cidade: espaço de cidadania, 27 de fevereiro de 2004. Disponível em: <www.rc.unesp.br/igce/planejamento/publicacoes/.../rbraga11.pdf>. Acesso em: 10 out 2012.

Caracciolo, B. A Feminina, Gazeta de Pesqueira, Pesqueira- PE, 15 de fevereiro de 1903, pp.2.

CARDOSO, Severino. Instrução e Educação. A Co-educação dos sexos. A Verdade. Recife-PE, 23 de nov. de 1872, pp.2-3.

CARvalHO, Xavier. A Situação da Mulher. Jornal do Recife, Recife- PE, 22 de abr. de 1890, p.1.

CENTI, Nina. Revista Pilhéria (3:95), Recife-PE, 1923, pp.14.

COSTA, Suely. Onda, rizoma e "sororidade" como metáforas: representações de mulheres e dos feminismos (Paris, Rio de Janeiro: anos 70/80 do século $\mathrm{xx}$ ). INTERthesis (6:2), Florianópolis-SC, 2009, pp.1-29.

DuARTE, Constância Lima. Nísia Floresta: a primeira feminista do Brasil. Florianópolis-SC, Ed. Mulheres, 2005.

Estatutos do Centro Protetor dos Operários em Pernambuco. Cap. VII. Secção Feminina Art. 46. Aurora Social. Órgão do Operariado. Recife, 21 de dezembro de 1903, pp.3.

FERREIRA, Aurélio Buarque de Hollanda. Novo Dicionário da Língua Portuguesa. Rio de Janeiro, Nova Fronteira, 1986.

Foucault, Michel. Ditos e escritos: ética, sexualidade, política. vol. 5. Rio de Janeiro, Forense Universitária, 2004.

Fragoso, Maria. A Questão da Mulher. Recife, Imprensa Industrial, 1904. Gazeta de Pesqueira. Pesqueira-PE, 1903.

FREYRE, Gilberto. Manifesto Regionalista. Recife, 1926. Disponível em: http: $<$ www.arq.ufsc.br/arq5625/modulo2modernidade/manifestos/manifestor egionalista.htm. >. Acesso em: 02 set 2012.

GriLlo, M. Ângela de F. Ave Libertas: o movimento abolicionista feminino de Pernambuco. In: Anais do I Seminário Internacional Enfoques Feministas e o Século XXI: Feminismo e Universidade na América Latina. Salvador, 2005, pp.01-14. 
cadernos pagu (42) Noemia Maria Q. P. da Luz e Alcileide C. do Nascimento 367

HAHNER, June. Emancipação do sexo feminino: a luta pelos direitos da mulher no Brasil, 1850-1940. Florianópolis-SC, Ed. Mulheres; Santa Cruz do Sul, Edunisc, 2003.

HARAWAY, Donna. Saberes localizados: a questão da ciência para o feminismo e o privilégio da perspectiva parcial. Cadernos Pagu (5) Campinas- SP, Núcleo de estudos de Gênero - Pagu/Unicamp, 1995, pp.07-41.

Hemmings, Clare. Contando estórias Feministas. Revista Estudos Feministas (17:1), Florianópolis-SC, UFSC, 2009, pp.215-241.

HoBSBAWN. Eric. A Era dos Impérios (1875-1914). Rio de Janeiro-RJ, Paz e Terra, 1988.

JOAQUim Nabuco. Diários. V.1. Rio de Janeiro, Bem-Te-Vi Produções Literárias/Recife, Ed. Massangana, 2005.

LEÃO, E. As Mulheres e a Política. A Patria, Garanhuns - PE, 11 de out. 1911, p.1.

LEITE, Márcia Maria da Silva Barreiros. Entre a tinta e o papel: Memórias de leituras e escritas femininas na Bahia (1870-1920). Salvador-BA, Quarteto, 2005.

Lemos, Layette. Pelo Feminismo, Revista Polyantho (III:11-12), Recife, 1907, pp.3.

LUZ, Noemia Maria Queiroz Pereira da. Os caminhos do olhar: circulação, propaganda e humor - Recife (1880-1914). Tese (doutorado) em História, Universidade Federal de Pernambuco, 2008.

Melo, Oscar. Recife Sangrento. Recife, s/ed, 1938.

MORAIS. Maria Luíza Nóbrega. Presença feminina no jornalismo pernambucano: Dos primórdios a regulamentação profissional. Disponível em: $<$ http://www.intercom.org.br/papers/outros/hmidia2007/resumos/R01 56-1.pdf > . Acesso em: 15 jul. 2011.

NASCIMENTO, Alcileide Cabral e LUZ Noemia M. Q. Pereira da. Liberdade, transgressão e trabalho: o cotidiano das mulheres na cidade do Recife (1870-1914). Revista Territórios e Fronteiras (1:1), Cuiabá-MT, 2012, pp.126-149. 
368 O debate em torno da emancipação feminina no Recife (1870-1920)

NASCIMENTO. Luis do. História da Imprensa em Pernambuco, vol. 7, Recife, Imprensa Universitária, 1966.

PEDRO, Joana. Relações de Gênero como categoria transversal na historiografia contemporânea. Revista Topoi 12(22), Rio de Janeiro, jan-jun 2011, pp.270-283.

PERNAMBUCO, Leis e Decretos. Lei $\mathrm{n}^{\circ}$. 13, de 14 de nov. 1891. SFR. SNT. pp.01-03.

PERROT, Michelle. As mulheres ou os silêncios da história. Bauru-SP, EDUSC, 2005.

PINTO, Céli Regina J. Uma história do feminismo do Brasil. São Paulo, Ed. Fundação Perseu Abramo, 2002.

PONTUAL, Virgínia; PICCOLO, Rosane. A demolição e a conservação das áreas centrais: planos, leis e transformações morfológicas no Recife, Brasil. Diez años de cambios en el Mundo, en la Geografía y en las Ciencias Sociales, 1999-2008. Actas del X Coloquio Internacional de Geocrítica, Universidad de Barcelona, 26 a 30 de mayo de 2008. Disponível em: <http://www.ub.edu/geocrit/-xcol/124.htm>. Acesso em: 01 nov 2012.

RAgO, Margareth. Do Cabaré ao Lar. Rio de Janeiro, Paz e Terra, 1985.

RAGO, Margareth. Adeus ao feminismo. Cadernos AEL, n 3/4, 1995/ 1996, pp.8. Disponivel em: <http://www.ifch.unicamp.br/ael/websiteael_publicacoes/cad-3/Artigo-1-p11.pdf>. Acesso em: 20 out 2011.

RAGO, Elisabeth Juliska. Francisca Praguer Fróes e a igualdade dos sexos. Labrys - Estudos Feministas, Brasília/DF, ago/dez 2005, pp.1-26.

RECIFE Illustrado. Recife-PE, 1888.

REZENDE, Antônio Paulo. O Recife: história de uma cidade. Recife- PE, Fundação de Cultura Cidade do Recife, 2002.

ScotT, Joan. A Cidadã Paradoxal. As feministas francesas e os direitos do homem. Florianópolis- SC, Ed Mulheres, 2002.

SILVA, Leonardo Dantas. A abolição em Pernambuco. Recife, Ed. Massangana, 1988. 
cadernos pagu (42) Noemia Maria Q. P. da Luz e Alcileide C. do Nascimento 369

SIQUEIRA, Elizabeth A. Santos et al. Um discurso feminino possivel: pioneiras da imprensa em Pernambuco (1830-1910). Recife, Editora Universitária da UFPE, 1995.

SOBRE o Feminismo. Jornal da Semana, Espinheiro - PE, 24 de janeiro de 1911, p.1.

SolHET, Rachel. A conquista do espaço público. In: PEDRO, Joana. Nova História das Mulheres no Brasil. São Paulo, Contexto, 2012, pp.218-237.

TELES, Maria Amélia de Almeida. Breve história do feminismo no Brasil. São Paulo, Brasiliense, 1999.

VASCONCELlOS, Maria Augusta C. Meira de. Uma Decisão Injusta. Jornal do Recife, Recife-PE, 25 de abril de 1890, p.2.

VERFUS, Anne. Voto familiarista e voto familiar: contribuição para o estudo do processo de individualização das mulheres na primeira metade do século XIX. In: CANÊDO, Letícia Bicalho (org.). O sufrágio universal e a invenção democrática. São Paulo, Estação Liberdade, 2005, pp.405-433.

\section{Periódicos}

Aurora Social. Órgão do Operariado. Recife- PE, 1903.

O Bem-te-vi. Recife- PE, 1913.

Cri Cri. Recife-PE, 1908.

Gazeta de Pesqueira. Pesqueira- PE, 1903.

Helios. Revista Literária e Feminista. Recife- PE, 1911.

Jornal da Semana. Espinheiro-PE, 1911.

Jornal do Recife, Recife- PE, 1890.

O Lidador. Hebdomadário, Noticioso, Literário, Agrícola e Comercial. Vitória - PE. 1912.

Mephistophesles. Pernambuco, 1882.

A Opinião. Pernambuco, 1880.

A Patria. Garanhuns- PE, 1911. 
370 O debate em torno da emancipação feminina no Recife (1870-1920)

A Pátria. Orgam defensor das classes laboriosas. Recife- PE,1909.

O Pharol. Bananeiras- BA, 1909.

O Prego. Recife- PE, 1916.

A Província. Órgão do Partido Liberal. Recife- PE, 1877.

Província de Pernambuco. Folha Liberal. Recife- PE, 1879.

A Reforma. Órgão do Partido Revisionista. Recife- PE, 1904.

Revista Pilhéria. Recife-PE, 1923,

Revista Polyantho. Recife, PE, 1907.

A Verdade. Recife- PE, 1872. 